\title{
Teaching in 2020: the impact of neuroscience
}

\section{Uta Frith}

University College, London, UK

\section{Why is the brain important when we plan for future education?}

The brain has evolved to educate and to be educated, often instinctively and effortlessly. The brain is the machine that allows all forms of learning to take placefrom baby squirrels learning how to crack nuts, birds learning to fly, children learning to ride a bike and memorising times-tables to adults learning a new language or mastering how to program a video recorder. Of course, the brain is also our natural mechanism that places limits on learning. It determines what can be learned, how much and how fast.

\section{How will progress be made?}

Basic research has already shed a great deal of light on how the brain learns. Recent advances in technology have provided an amazing tool for neuroscientists to discover more about how the human brain functions. Techniques such as brain imaging, which measures activity in the brain as humans perform a certain task, have significantly pushed forward our knowledge of the brain and mind. Brain scientists can now offer some understanding of how the brain changes when it acquires and uses new skills throughout life.

\section{What progress can we expect?}

Knowledge of how the brain learns will have a great impact on education by 2020. We will have a reasonable understanding of the brain mechanisms that underlie learning and teaching, and the subtle processes that go on between teacher and learner. We will know about sensitive periods that could be used to make learning super-efficient. We will know about the nature of the learning difficulties in developmental disorders and there will probably be novel means of overcoming them. For instance, microchips might be implanted to enhance cognitive function. The brain basis of our social and emotional life 
will be revealed and this may well have consequences for improving social interactions.

\section{Plasticity}

The brain's plasticity - its capacity to adapt continually to changing circumstancesdepends critically on how much it is used: use it or lose it. Research on plasticity suggests that the brain is well set up for lifelong learning and adaptation to the environment, and that educational rehabilitation in adulthood is possible and well worth investment. On the other hand, the research also suggests that there is no biological necessity to rush and start formal teaching earlier and earlier. Rather, late starts might be reconsidered as perfectly in time with natural brain and cognitive development.

\section{Individualised teaching}

Although plasticity is a ubiquitous and baseline state, there are clearly individual differences, which probably depend partly on genes and partly on the environment. Eventually, we will be able to know about the natural predispositions of children and how these predispositions (or lack of them) can be built on by teaching. Neuroscience techniques will be available to track the effects of learning in the developing brain in individual children. We will be able to decide which teaching method, or indeed which teacher, is best suited to each child. If we know this then we can individualise teaching just as we will be able to individualise medicine by 2020. This means that throughout life each person can receive the health advice and the education advice that is exclusively relevant to them. Mental health and physical health will become part of education.

\section{Disorders}

Neuroscience will reveal the basis of academic skills such as reading, writing and maths, and what to do about children at risk of failing to learn these skills. It will be possible to monitor in the brain the changes that occur with learning and this should help us to circumvent learning difficulties inherent in neuro-developmental disorders. Brain science could transform special needs education by enabling us to design programmes that optimise learning for people of all needs and all ages. Once we understand the different ways of learning, we will be able to find the optimal pace of learning for each child and can take them to the limit of their capacity to learn.

\section{Understanding the process of teaching}

Judging the pace of learning will depend on understanding the interaction between teacher and learner, not only the capacity of the learner. One of the major contributions neuroscience is capable of making is illuminating the nature of teaching itself. For example, we already know that a foreign accent is almost bound 
to be present in a second language if learning occurs after the age of four or five. Recent evidence has shown that critical periods for learning the sounds of speech can be extended beyond their natural limit, but only by active teaching from a live human, not by taped or videoed recordings.

\section{Social emotional development}

Even if live teaching continues to be important, if teaching can be individually delivered to millions of terminals, and if a child's performance can be monitored continuously, then choices become greater, and geography will matter less. Children's experience of playing and working in groups will need to be fostered in new ways. By 2020 neuroscience will have revealed the brain basis of our emotions, our sense of justice and our moral sensitivity, and we will be able to spot individual weaknesses using brain scans. These advances may well lead to new approaches to teaching skills that derive from these critical capacities.

\section{Limits}

Predicting the future is bound to be wrong. We have no idea what new techniques might revolutionise neuroscience. Despite the progress we expect, we will still grapple with the really difficult problems - those that pedagogues have identified long ago. In his famous essay on the education of children, written in 1572, Montaigne wishes for 'a well-formed rather than a well-filled intellect'. We can heartily agree, but do we know what we mean by a well-formed intellect? Perhaps neuroscience will help us answer some parts of this question.

\section{Note on contributor}

Uta Frith is Professor of Cognitive Development at University College, London and Deputy Director of the its Institute of Cognitive Neuroscience, where she carries out research on developmental disorders, in particular autism and dyslexia. Her publications include: Autism: explaining the enigma (2nd edn, 2003), and Autism and Asperger Syndrome (1991). She is passionately interested in explaining concepts from brain science to a wider public and in particular to teachers, as she believes in the relevance of these concepts to education. With Sarah-Jayne Blakemore she recently published Teaching the brain to learn: lessons for education (Oxford, Blackwell, 2005). Uta Frith has received recognition for her work on developmental disorders by having been elected a Fellow of the British Academy, the Academy of Medical Sciences and the Royal Society. 


\section{Authors Queries}

\section{Journal: Journal of Education for Teaching}

Paper: 127994

Title: Teaching in 2020: the impact of neuroscience

\section{Dear Author}

During the preparation of your manuscript for publication, the questions listed below have arisen. Please attend to these matters and return this form with your proof. Many thanks for your assistance

\begin{tabular}{|l|l|l|}
\hline $\begin{array}{l}\text { Query } \\
\text { Reference }\end{array}$ & Query & Remarks \\
\hline 1 & $\begin{array}{l}\text { Author's correspondence } \\
\text { address? }\end{array}$ & \\
\hline 2 & $\begin{array}{l}\text { Autism: explaining the enigma: } \\
\text { publisher's name and city? }\end{array}$ & \\
\hline 3 & $\begin{array}{l}\text { Autism and Asperger Syndrome: } \\
\text { publisher's name and city? }\end{array}$ & \\
\hline
\end{tabular}

